\title{
Z zagadnień słownictwa ogólnotunezyjskiego
}

\section{On some problems of the Tunisian lexical stock}

\author{
Jamila Oueslati \\ Instytut Językoznawstwa, Uniwersytet im. Adama Mickiewicza \\ al. Niepodległości 4, 61-874 Poznań \\ jamilaweslati@yahoo.com
}

\begin{abstract}
Abstrakt
Artykuł poświęcony jest niektórym problemom leksyki tunezyjskiej w aspekcie kontaktów tunezyjskiej wspólnoty dialektalnej z innymi wspólnotami językowymi. Objaśniwszy sens terminów tunezyjska wspólnota dialektalna, ogólnotunezyjski oraz arabska wspólnota językowa przechodzimy do kontaktów ogólnotunezyjskiej wspólnoty dialektalnej z innymi wspólnotami językowymi, poddając analizie jedynie część słownictwa pochodzenia arabskiego i francuskiego.
\end{abstract}

\section{Wstęp}

Kontakty między wspólnotami językowymi pozostawiają ślady przede wszystkim w słownictwie, które tworzy system stosunkowo otwarty (por. Zabrocki 1963). Oznacza to między innymi, że języki łatwiej zapożyczają słowa niż np. głoski, morfemy gramatyczne. Prawidłowość tę potwierdza również język arabski, a w szczególności dialekt tunezyjski. Chociaż długotrwały i intensywny kontakt między językami może prowadzić również do przejmowania obcych głosek bądź jednostek gramatycznych.

W tym miejscu należy zaznaczyć, że niniejsza praca bazuje przede wszyskim na obserwacjach własnych jako osoby pochodzącej z Tunezji, a nie na korpusie tekstów np. literackich. Ponadto należy dodać, że badania nad dialektem tunezyjskim, szczególnie nad jego słownictwem, są jeszcze słabo rozwinięte. Za najlepszą pracę na tym polu można uznać książkę Talmoudi (1981).

\section{Tunezyjska wspólnota dialektalna (TWD)}

Przez wspólnotę językową będziemy rozumieć za L. Zabrockim (1956) grupę ludzi, w której obiektywnie istnieją warunki dla przekazywania informacji za pomocą względnie jednolitego języka. Na obszarze języka arabskiego można wyróżnić szereg wspólnot językowych. Nasze rozważania rozpoczniemy od tunezyjskiej wspólnoty dialektalnej (TWD). Szczególnie istotne dla naszych celów będa relacje między arabskimi wspólnotami dialektalnymi a ogólnoarabską wspólnotą językową (OAWJ). 
Przez dialekt ogólnotunezyjski (DOT) będziemy rozumieć dialekt języka ogólnoarabskiego, który obsługuje tunezyjską wspólnotę dialektalną i który występuje w kilku odmianach (dialektach lokalnych) wzajemnie zrozumiałych.

Współczesna tunezyjska wspólnota dialektalna obejmuje nie tylko mieszkańców Tunezji, ale również wszystkich tych ludzi, którzy są w stanie posługiwać się dialektem ogólnotunezyjskim. Warto przypomnieć, że w ramach tej wspólnoty dialektalnej można wyróżnić wiele odmian lub dialektów lokalnych. Do nich należą między innymi:

(i) grupa północno-wschodnia: Tūnis, Binzart, Al-Waṭan al-Qiblī,

(ii) grupa północno-zachodnia: Al-Kāf, Bāja, Ṭabarqa, Silyāna,

(iii) grupa dialektów wybrzeża: Sūsa, Monastīr, Mahdiyya,

(iv) grupa miasta Sfaks i okolic,

(v) grupa południowo-wschodnia: Gābis, Midnīn, Ṭâtāīwīn,

(vi) grupa połuniowo-zachodnia: Gafșa, Tūzir,Nafța.

\section{Kontakty TWD $\mathrm{z}$ innymi wspólnotami językowymi}

TWD pozostawała i nadal pozostaje w kontaktach językowych $\mathrm{z}$ innymi wspólnotami językowymi. Kontakty te są dość specyficznej natury i poniżej wspomnimy z braku miejsca tylko o niektórych ich aspektach.

\subsection{Arabska wspólnota językowa (AWJ)}

TWD funkcjonuje $\mathrm{w}$ ramach arabskiej wspólnoty językowej. Ta ostatnia obejmuje wszystkich ludzi, którzy są $\mathrm{w}$ stanie posługiwać się językiem arabskim w celu przekazywania informacji. Termin język arabski będziemy rozumieć w szerszym sensie, to znaczy nie rozstrzygając tutaj czy chodzi o język potoczny, czy bardziej formalny, czy też o jakąś odmianę dialektalną. Tak więc przez język arabski będziemy rozumieć środek komunikacji względnie zrozumiały dla uczestników aktów komunikacji.

Arabska wspólnota językowa jest w dużym stopniu zróżnicowana, co oznacza, że możemy wyodrębnić w niej różne podwspólnoty, które są wyznaczane przez odpowiednie faktory tak językowe, jak i pozajęzykowe. Do faktorów tych należy zaliczyć między innymi: geograficzne, społeczne, religijnie, polityczne, naukowe. Przykładowo ludzie, którzy są w stanie posługiwać się arabskim językiem literackim w mowie i piśmie, tworzą też odpowiednią podwspólnotę językową. Tak więc w ramach AWJ funkcjonują różne wspólnoty dialektalne, socjolektalne, etnolektalne itp.

\subsection{Pozaarabskie wspólnoty językowe}

TWD bądź też niektóre jej podwspólnoty pozostały w kontakcie z takimi wspólnotami językowymi, jak: hiszpańska, turecka, włoska i francuska. Najdłuższe i najważniejsze kontakty miały miejsce właśnie $\mathrm{z}$ francuską wspólnotą językową (FWJ). Kontakty te doprowadziły do znacznego wpływu FWJ na TWD do tego stopnia, że przynajmniej duża część Tunezyjczyków stała się członkami FWJ. W niniejszym artykule zajmujemy się jedynie słowami pochodzenia arabskiego i francuskiego.

\section{Slownictwo pochodzenia arabskiego}

Wśród słów pochodzenia arabskiego w dialekcie ogólnotunezyjskim należy odróżnić dwie grupy, tj.:

i. słowa odziedziczone $z$ języka arabskiego oraz

ii. słowa zapożyczone z języka arabskiego. 


\subsection{Slowa odziedziczone $\mathrm{z}$ arabskiego}

W słownictwie odziedziczonym z języka arabskiego można wyodrębnić między innymi pięć kategorii leksykalnych, $\mathrm{z}$ których każda zostanie poniżej odpowiednio zegzemplifikowana.

\subsubsection{Słowa odziedziczone $\mathrm{z}$ języka arabskiego bez zmian semantycznych}

Celem egzemplifikacji braku zmian semantycznych $\mathrm{w}$ odziedziczonym słownictwie posłużymy się wyszczególnionymi w poniższej tabeli słowami, a następnie zilustrujemy ich użycie odpowiednimi frazami.

\begin{tabular}{|c|c|c|}
\hline DOT & ARABSKI & ZNACZENIE \\
\hline marḥbe & marḥaban & witaj!, cześć! \\
\hline ehle & ahlan & witaj! \\
\hline s-selem & as-salām & pokój \\
\hline hōìr & hayr & $\begin{array}{ll}\text { coś } & \text { dobrego, } \\
\text { dobroczynność } & \end{array}$ \\
\hline barka & barakat & błogosławieństwo \\
\hline 1-ḥamd & al-ḥamd & chwała \\
\hline șbāḥ & șabāḥ & rano \\
\hline $\mathrm{mse \overline {e }}$ & masā & wieczór \\
\hline līle & laylat & noc \\
\hline marḥbe, marḥbe bīk & marḥaban, marḥaban bik(a,i) & witaj!, cześć! \\
\hline ehle, ehle bīk & ahlan, ahlan bik(a,i) & witaj! \\
\hline ehle w sehle & ahlan wa sahlan & witaj! \\
\hline es-selemu aleykum & as-salāmu alaykum & pokój wam! \\
\hline wa- aleykum s-selēm & wa- alaykum as-salām & pokój z tobą! \\
\hline le bēs & lā ba s & w porządku \\
\hline b-hֵīr & bi-hַayr & dobrze, świetnie \\
\hline 1-ḥamdū-lle & al-ḥamdu li-llāh & $\begin{array}{lll}\text { chwała } & \text { Bogu!, dzięki } \\
\text { Bogu! } & \end{array}$ \\
\hline barka- llahu fîk & bāraka allāhu fīk(a,i) & niech cię Bóg błogosławi \\
\hline bhīir, barka- llahu fîk & bih̄ayr, bāraka allāhu fīk(a,i) & $\begin{array}{l}\text { dobrze, niech cię Bóg } \\
\text { błogosławi }\end{array}$ \\
\hline 1-ḥamd-illa 'le slēmtik & $\begin{array}{l}\text { al-ḥamdu li-llāh 'la } \\
\text { salāmatik }(a, i)\end{array}$ & $\begin{array}{lll}\text { dzięki } & \text { Bogu } & \text { jesteś } \\
\text { zdrowy/a } & & \end{array}$ \\
\hline ṣbāḥ 1-h̄īr & șabāḥ al-hূayr & dzień dobry \\
\hline msē 1-h̄īr & masā al-hֵayr & dobry wieczór \\
\hline taṣbḥu le hoīr & tuṣbiḥūn ala hূayr & dobra noc \\
\hline līlitkum s ìde & laylatukum sa'īdat & dobrej nocy! \\
\hline sellim 'le ehlik & sallim ala ahlika & pozdrów swoją rodzinę \\
\hline sellim 'le -l'āyle & 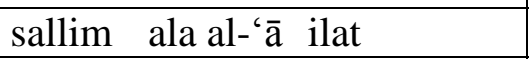 & pozdrów rodzinę \\
\hline rabbi m‘āk & rabbī ma'ak(a, i) & $\begin{array}{l}\text { niech cię Bóg prowadzi! } \\
\text { (dosł. Pan z tobą) }\end{array}$ \\
\hline kul 'àm w intūme b-h̄īr & kulu 'ām wa antum bi-hֵayr & wszystkiego najlepszego \\
\hline
\end{tabular}




\subsubsection{Słowa odziedziczone $\mathrm{z}$ języka arabskiego o rozszerzonym znaczeniu}

Zachowanie i rozszerzenie znaczenia można obserwować na podstawie poniższych słów i ich użycia w przytoczonych frazach.

\begin{tabular}{|c|c|}
\hline DOT & ARABSKI \\
\hline $\begin{array}{l}\text { mše } \\
\text { mše li-l-'attārr 'poszedł do sklepu', } \\
\text { mše li-l-h̆idme 'poszedł/pojechał do } \\
\text { pracy', } \\
\text { l-wled bde yimši 'chłopiec zaczął } \\
\text { chodzić', } \\
\text { mše l-Tünis 'pojechał (udał się w podróż) } \\
\text { do Tunisu', } \\
\text { mše li-Frānsa 'wyjechał (wyemigrował) } \\
\text { do Francji'. }\end{array}$ & maša 'chodzić, maszerować, odejść' \\
\hline 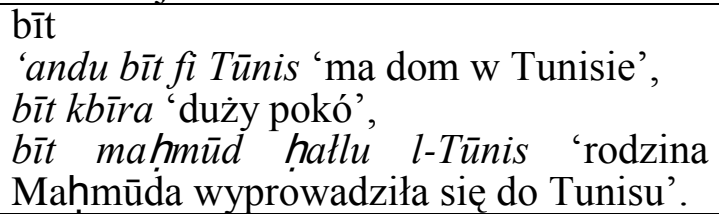 & bayt 'dom, mieszkanie, apartament' \\
\hline $\begin{array}{l}\text { blēd } \\
\text { blēedi b 'ìde 'mój kraj jest daleko', } \\
\text { mšst l-wost li-blēd 'poszedłem/poszłam, } \\
\text { jechałem/am, pojechałem/am do centrum } \\
\text { miasta', } \\
\text { rawwaht li-l-blēd 'wracałem/am do } \\
\text { domu rodzinnego'. }\end{array}$ & bilād 'kraj, państwo, miasto, miejscowość' \\
\hline $\begin{array}{l}\text { qrāye } \\
\text { qrīt ktēb 'czytałem/am książkę', } \\
\text { naqra fi-l-ğèm 'a 'studiuje na } \\
\text { uniwersytecie'. }\end{array}$ & qirā'at 'czytanie, recytacja, czytanie Koranu' \\
\hline 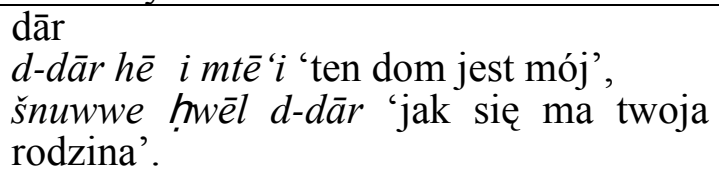 & $\begin{array}{l}d \bar{a} r \text { 'dom, budynek, budowla, mieszkanie, } \\
\text { rezydencja, region, rejon, kraj' }\end{array}$ \\
\hline $\begin{array}{l}\text { šedd } \\
\text { šedd fi d-drūğ 'trzymał się schodów', } \\
\text { šeddhe min yidhe 'trzymał ją za rekę,', } \\
\text { nšid boq'a fi-l-mitro 'zajmuję dla siebie } \\
\text { lub dla kogoś miejsce w tramwaju', } \\
\text { nšid l-hidme fi-l- 'ašra 'zaczynam pracę o } \\
\text { dziesiątej’', } \\
\text { šedd hidme 'znalazł pracę i zaczął } \\
\text { pracować'. }\end{array}$ & $\begin{array}{l}\text { šadda 'wzmacniać, umacniać, ciaggnać, wlec, } \\
\text { związywać, przywiązywać, umocowywać, } \\
\text { rozciągać, naciągać, trzymać się' }\end{array}$ \\
\hline $\begin{array}{l}\text { 'mal } \\
\text { ēš ‘'amil 'jak się masz', } \\
\text { na 'mil dūšs 'biore prysznic', } \\
\text { na'mlū qahwa? 'napijemy się kawy?', } \\
\text { ya 'mil hēle 'robi problemy', } \\
\text { ta 'mil 'ayle '(kiedyś) będziesz mieć } \\
\text { swoją rodzinę', } \\
\text { mel hēdi 'miał wypadek'. }\end{array}$ & $\begin{array}{l}\text { 'amila 'robić, czynić, działać, wykonywać, } \\
\text { produkować, realizować, dążyć, zmierzać, } \\
\text { starać się, próbować' }\end{array}$ \\
\hline 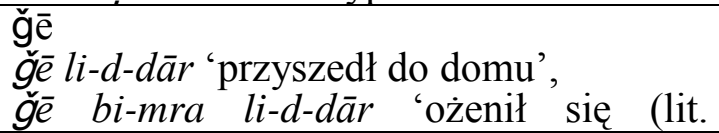 & $\begin{array}{l}\text { ğā a 'przychodzić, przybywać, przyjeżdżać, } \\
\text { przyprowadzać, przynosić' }\end{array}$ \\
\hline
\end{tabular}




\begin{tabular}{|c|c|}
\hline 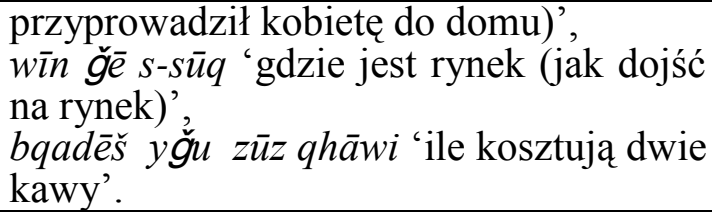 & \\
\hline $\begin{array}{l}\text { hhluw } \\
\dot{t} \text {-tēy hluw 'herbata jest słodka', } \\
\text { šrit h̆hluw l- id 'kupiłem/am słodycze } \\
\text { świąteczne', } \\
\text { bneyye hluwwe 'miła } \\
\text { dziewczyna'. }\end{array}$ & hulw 'słodki' \\
\hline 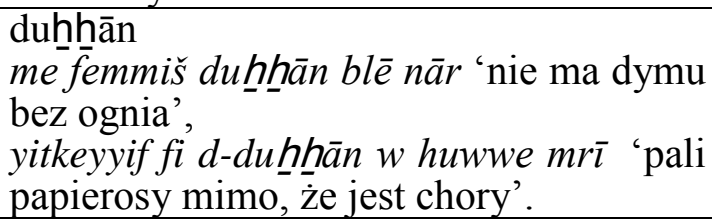 & duhhhān 'dym' \\
\hline 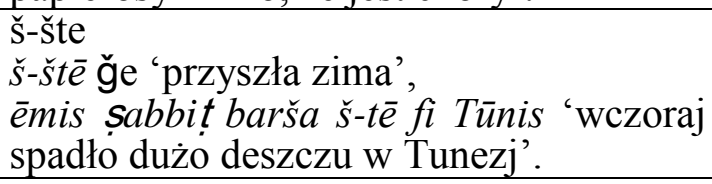 & aš-šitā 'zima' \\
\hline
\end{tabular}

\subsubsection{Słowa dialektu tunezyjskiego bazujące na rdzeniu arabskim z tunezyjskim} formantem słowotwórczym niewystępującym w ogólnoarabskim

Do takich formantów słowotwórczych należą między innymi sufiksy $-\overline{\boldsymbol{e}} \overline{\boldsymbol{s}}$ i $-\check{\boldsymbol{s}}$, które używane są wyłącznie w pytaniach.

Sufiks '-ēš'

$>$ hluwwēš 'czy to jest miło tak mówić, robić, zachowywać się?', por. ar. hulw 'słodki',

$>$ waqtēš 'kiedy, o której godzinie?', por. ar. waqt 'czas',

$>$ kifěš 'jak?', por. ar. kajfa 'jak',

femmēes lub temmēšs 'czy jest?', por. ar. tamma 'jest'.

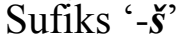

$>$ hẹ̆ğtikiš 'czy potrzebujesz?', por. ar. hāğă 'potrzeba',

$>\quad$ endikiš 'czy masz?', por. ar. inda 'mieć',

$>\quad$ iğbikiš 'czy lubiłeś/aś' lub ‘czy podobał ci się?’, por. ar. a ğaba 'lubić, podobać się, zachwycać,

$>$ bditiš 'czy zaczynałeś', por. ar. bada a 'zaczynać'.

\subsubsection{Słowa dialektu tunezyjskiego utworzone od słów arabskich i wykazujące znaczne zmiany fonetyczne i morfologiczne}

Chociaż powyżej przytoczone słowa tunezyjskie wykazują zmiany fonetyczne, to poniżej przedstawione słowa tunezyjskie są fonetycznie bardzo odległe od słów arabskich.

$>$ wīn lub fïn 'gdzie', por. ar. ayna 'gdzie',

$>$ lwīn 'dokąd', por. ar. ilä 'do', ayna 'gdzie',

$>\quad l \bar{a} s$ s lub lwēss 'dlaczego', por. ar. limā $\underline{a} \bar{a}$ 'dlaczego',

$>$ mnīn 'skąd', por. ar. min 'od, z', ayna 'gdzie',

$>\boldsymbol{b l e ̄ s ̌ ~ ' b e z p ł a t n i e ' , ~ p o r . ~ a r . ~ b i l a ̄ ~ ' b e z ' , ~ s ̌ a y ~ ' c o s ́ ' , ~}$

$>\boldsymbol{h} \overline{\boldsymbol{e}} \overline{\boldsymbol{\imath}}$ 'jestem (lit. to ja, ja tu)', por. ar. $\boldsymbol{h} \overline{\boldsymbol{a}} \boldsymbol{a} \overline{\boldsymbol{n}} \overline{\boldsymbol{a}}$ 'to ja'.

\subsubsection{Słowa odziedziczone $\mathrm{z}$ języka arabskiego $\mathrm{z}$ częściową lub całkowitą zmianą semantyczną}

Przedstawione poniżej słowa tunezyjskie są przykładami na przesunięcie znaczenia

$>$ hìt 'ryba', por. ar. hiüt 'wieloryb',

> mektib 'szkoła', por. ar. maktab 'biurko, biuro, punkt informacyjny',

$>\quad \boldsymbol{a t t a ̄ r}$ ' 'właściciel małego sklepu spożywczego', por. ar. atțār 'handlarz wonnościami lub właściciel drogerii', 
> ğirbi 'osoba z miasta ğirba, położonego na południu Tunezji, handlarz (ponieważ większość handlarzy w Tunezji pochodzi z miasta ğirba)', por. ar. ğirbī 'osoba z miasta ğirba',

$>\quad \breve{s} \boldsymbol{r} \bar{a} \boldsymbol{b}$ 'alkohol', por. ar. ̌̌arāb 'wino',

> $\boldsymbol{b} \underline{h} \bar{l} l$ 'leniwy', por. ar. $\boldsymbol{b} \boldsymbol{a} \underline{h} \bar{\imath} l$ 'skapy, skapiec'.

\subsection{Słowa zapożyczone $\mathrm{z}$ języka arabskiego}

Omawiana tu grupa słów obejmuje zapożyczenia z różnych dziedzin współczesnego języka arabskiego. Dla celów niniejszego artykułu podamy przykłady zaczerpnięte $\mathrm{z}$ takich dziedzin, jak: sprzęt elektroniczny, instytucje kulturalne, media, życie politycznospołeczne, urządzenia techniczne. Wśród tych słów można wyróżnić przynajmniej dwie grupy:

i. słowa obce fonetycznie zarabizowane,

ii. słowa bazujące na rdzeniu arabskim (kalki, rozszerzanie znaczenia).

Przykłady słów należących do tych dwu grup zawiera poniższa tabela.

\begin{tabular}{|c|c|c|}
\hline DOT & ARABSKI & $\begin{array}{l}\text { ZNACZENIE W JĘZYKU } \\
\text { POLSKIM }\end{array}$ \\
\hline t-tiknīk & at-tiknīk & technik \\
\hline telvze & talfaza, tilifizyūn, tilfāz & telewizor \\
\hline radyūn & rādyū & radio \\
\hline tiligram & tiliğ̈rāf & telegram \\
\hline telifūn & tilifūn & telefon \\
\hline ǧerīde & ğarīdat & gazeta \\
\hline lenternet & al-antirnìt & Internet \\
\hline vìdyo & fìdyū & video \\
\hline kompyūtir & kūnbyūtar & komputer \\
\hline masrah & masrah & teatr \\
\hline opira & ūbirā & opera \\
\hline sinima & sīnamā & kino \\
\hline museğle & musağǧilat, musağğil & magnetofon \\
\hline pyāno & biyānō & pianino \\
\hline fîlim & film & film \\
\hline muwāțin & muwāțin & obywatel, rodak \\
\hline wațan & wațan & ojczyzna, kraj ojczysty, dom \\
\hline ša $b$ & ša $b$ & naród, nacja, lud \\
\hline ǧumhuriyye & ǧumhūriyyat & republika \\
\hline ištirākiyye & ištirākiyyat & socjalizm \\
\hline šuyū iyye & šuyū iyyat & komunizm \\
\hline d-dimoqratiyye & ad-dīmūqrātiyyat & demokracja \\
\hline enēniyye & anāniyyat & egoizm \\
\hline sērūḥ & șārūḥ & rakieta \\
\hline țayyāra & tayyārat & samolot \\
\hline ḡawwāșa & ḡawwāșat & lódź podwodna \\
\hline debbēbe & dabbābat & czołg \\
\hline museddis & musaddas & pistolet, rewolwer \\
\hline
\end{tabular}

\section{Słownictwo pochodzenia francuskiego}

Znaczna liczba słów obcych w dialekcie tunezyjskim została zapożyczona z języka francuskiego. Język francuski pozostaje nadal w szerokim użyciu w Tunezji, a jego wpływ nie jest ograniczony jedynie do jednej czy dwóch dziedzin, jak dzieje się czasami w przypadku zapożyczeń $\mathrm{z}$ innych języków. W niektórych dziedzinach, często bardzo specjalistycznych, takich jak np. medycyna, prawo, polityka czy technika, notujemy dość dużo francuskich zapożyczeń. W tym kontekście warto zwrócić uwage jeszcze na inny 
aspekt wpływu języka francuskiego na dialekt tunezyjski. W Tunezji mianowicie nawet osoba, która nie potrafi czytać i pisać po francusku, używa często słów i wyrażeń z tego języka w sposób bardzo naturalny. Oznacza to, że słowa z języka francuskiego stały się częścią systemu leksykalnego dialektu ogólnotunezyjskiego (rzadko kto będzie zastanawiać się, skąd dany wyraz się w nim pojawił, czy też dlaczego używa się takiego, a nie innego słowa w języku mówionym).

Znaczna ilość słów pochodzenia francuskiego wykazuje pewien stopień fonetycznej arabizacji, co egzemplifikuje zamieszczona poniżej tabela:

\begin{tabular}{|l|l|l|}
\hline \multicolumn{1}{|c|}{ DOT } & FRANCUSKI & $\begin{array}{l}\text { ZNACZENIE W JĘZYKU } \\
\text { POLSKIM }\end{array}$ \\
\hline l-marši & le marché & targ, rynek \\
\hline l-būsța & la poste & poczta \\
\hline trīnu & train & pociąg \\
\hline blāṣa & place & miejsce \\
\hline šifūr & chaufeur & kierowca \\
\hline furšīṭa, furgīta & forchette & widelec \\
\hline kașarūna & cassarolle & rondel \\
\hline garsūn & garçon & kelner \\
\hline friğidēr & réfrigérateur & lodówka \\
\hline rūba & robe & sukienka \\
\hline ǧīb & jupe & spódnica \\
\hline kāska & casquette & czapka \\
\hline stīlu & stylo & długopis \\
\hline byēse & pièce & część składowa \\
\hline pubēle & poubelle & skrzynka, pojemnik \\
& śmierci \\
\hline mizīrye & misère & bieda \\
\hline nervūzi & nerveux & nerwowy \\
\hline tnirvīz & nervosité & nerwowość \\
\hline būlīs & police & policjant \\
\hline n-nūmru & le numérau & numer \\
\hline wtīl & hôtel & hotel \\
\hline trisīti & électricité & prąd \\
\hline burtmen & appartement & mieszkanie \\
\hline dakūrdu & d'accord & dobrze \\
\hline tinbri & timbre & znaczek pocztowy \\
\hline & & \\
\hline
\end{tabular}

Oprócz słów zapożyczonych z francuskiego, które uległy w jakimś stopniu fonetycznej arabizacji, występują również $\mathrm{w}$ dialekcie tunezyjskim słowa i zwroty używane w takiej samej formie i znaczeniu jak w języku francuskim, np.: ça $\boldsymbol{v a}$ 'dobrze', merçi 'dziękuję', centre ville 'centrum miasta', portable 'komórka', télécommande 'pilot telewizyjny', appatement 'mieszkanie', block 'blok mieszkalny', prise 'gniazdko', tapis 'dywan', cendrier 'popielniczka', sac 'torba', bagage 'bagaż', costume 'garnitur', tailleur 'kostium', voile 'welon', motif 'motyw', modèle 'model, wzór', poitrine 'pierś', publicité 
'reklama', moyen 'środek', pourcentage 'procent', privé 'prywatny', papier mouchoir 'chusteczka do nosa', pharmacien 'aptekarz', pharmacie 'apteka', ingenieur 'inżynier', médecin 'lekarz', psychiatre 'psychiatra', sage femme 'położna', plombier 'hydraulik', lycée 'liceum', moteur 'silnik', matricule 'tablica rejestracyjna', sachet 'torebka, woreczek, saszetka', moustache 'wąsy', muscle 'mięsień', bagette 'bagietka', toilette 'toaleta', lavabo 'umywalka'.

Czasami to samo słowo może występować w dwóch wariantach. Ludzie wykształceni, którzy posługują się językiem francuskim zawodowo, mówiąc dialektem, wymawiają słowa pochodzenia francuskiego zgodnie $\mathrm{z}$ wymową charakterystyczną dla tego języka, chociaż nie musi to być regułą. W rozmowach prywatnych natomiast moga stosować wymowę tych samych słów $\mathrm{w}$ formie zarabizowanej. Formy takie są w dialekcie tunezyjskim dość powszechne. W dużym stopniu stosowane są przez ludzi niewykształconych, nieznających języka francuskiego. $Z$ pewnością jest to przynajmniej jeden z czynników powodujących, że wymowa wyrazów zapożyczonych z języków

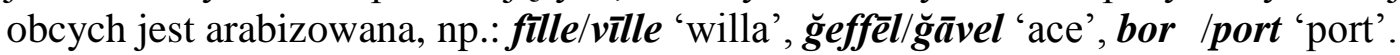

Warto też w tym miejscu zwrócić uwagę na to, że obecność języka francuskiego w rozmowach między użytkownikami może dotyczyć nie tylko pojedynczych słów, ale całych fraz bądź zdań wplatanych w tekst tunezyjski. Rozmowa może też odbywać się w całości w języku francuskim. Czasami, w zależności od wspólnoty komunikacyjnej, obserwuje się przechodzenie z jednego kodu na drugi.

\section{Słownictwo specyficzne dla dialektu ogólnotunezyjskiego}

Zasięg występowania niektórych słów ograniczony jest do dialektu ogólnotunezyjskiego. Mogą to być słowa o różnym pochodzeniu.

\begin{tabular}{|c|c|c|}
\hline DOT & ARABSKI & $\begin{array}{l}\text { ZNACZENIA W JEZZYKIM } \\
\text { POLSKIM }\end{array}$ \\
\hline mezrūb, zrib & asra'a & przyśpieszać, przyśpieszał \\
\hline bezzūle & tady & pierś (kobieca) \\
\hline ğrān & ḍafādi & żaby \\
\hline mitḡešišs & ḡāḍib & zły, gniewny \\
\hline bekkūšs & abkam & niemy \\
\hline fettiš, lewwiğ & baḥata & szukał \\
\hline barša, yēsir & katīir & dużo \\
\hline ba būṣ & dayl & ogon \\
\hline me temmēšs & ḡayr mawğūd & nie ma, nie jest \\
\hline karhba & sayyārat & samochód \\
\hline sūriyye & qamīṣ & koszula \\
\hline mungēle & sāa at & zegarek \\
\hline heǧğēl (e) & armal (at) & wdowiec, wdowa \\
\hline barra & idhab & pójść \\
\hline 1-barra & fĩ al-hāriğ, hāriğan & na zewnattrz, za granicą \\
\hline sēnye & bustān & ogród, sad \\
\hline
\end{tabular}




\begin{tabular}{|c|c|c|}
\hline nḡar & ḡaḍiba & zły, gniewny \\
\hline sfinnērye & ğazar & marchewka \\
\hline rāḥ & dahaba & $\begin{array}{l}\text { pójść, odejść, pojechać, } \\
\text { odjechać, wyjechać, oddalić } \\
\text { się, zniknąć }\end{array}$ \\
\hline biršni & ma z ṣağīr & koza \\
\hline ḥabrme, dūbme & ḥālamā, indamā & $\begin{array}{l}\text { kiedy tylko, jak tylko, gdy } \\
\text { tylko }\end{array}$ \\
\hline karmūs & tìn & figi \\
\hline berrēd & inā li-țabh్ aš-šāy & czajnik \\
\hline zēyle, zwēyil & dābbat, dawābb & $\begin{array}{l}\text { zwierzę, zwierzę pod } \\
\text { wierzch (koń, osioł, mul) }\end{array}$ \\
\hline Șawwir & ḥașala ( ala) & zarabiał \\
\hline țayyib & țabahna & gotował \\
\hline țāyib & nāọiǧg & ugotowany \\
\hline ğoḡme & ğur a & łyk \\
\hline kēf & rabwat & wzgórze, pagórek \\
\hline akkahu & faqat & tylko, jedynie \\
\hline bnīn & lad̄īo & smaczny \\
\hline bilgde & ğayyid & dobrze \\
\hline ěš, šnuwwe & mā $\underline{\mathrm{a} a}$ & co \\
\hline škūn & man & kto \\
\hline lēš & limād̄ā & dlaczego \\
\hline $\begin{array}{l}\text { qaddēšs, bqaddēš } \\
\text { gidděš, bgiddēšs }\end{array}$ & kam, bi-kam & ile, za ile \\
\hline sebbēle & ḥanafiyyat & kran \\
\hline mizyēn (e) & ğamīl (a) & ładny, ładna \\
\hline
\end{tabular}

\section{Uwagi końcowe}

Artykuł nasz miał na celu jedynie zasygnalizowanie pewnego sposobu podejścia do badania słownictwa $\mathrm{w}$ dialekcie ogólnotunezyjskim. Z braku miejsca nie mogliśmy przeprowadzić gruntowniejszej analizy poruszanych tu problemów. 


\section{Bibliografia}

Baccouche, T. 1972. Le phonème ' $\mathrm{g}$ ' dans les parlers arabes citadins de Tunisie. Revue tunisienne de Sciences Sociales 9 (30/31), 103-137.

Baccouche, T. ; Skik, H. ; Attia, A. 1969. Travaux de Phonologie, parlers de Djemmal, Gabès et Mahdia. Tunis: Cahiers du CERES.

Cantineau, J. 1951. Analyse du parler arabe d'El-Hâmma de Gabès. Bulletin de la Société Linguistique de Paris 47, 64105.

Danecki, J. 2000. Współczesny język arabski i jego dialekty. Warszawa: Dialog.

Ferguson, Ch. 1959. The Arabic koine. Language 25, 616-630.

Fischer, W. ; Jastrow, O. 1980. Handbuch der arabischen Dialekte. Wiesbaden: Harrassowitz.

Fischer, W. 1995. Zum Verhältnis der neuarabischen Dialekte zum Klasisch-Arabischen. W: Dialectologia arabica, Helsinki, 75-86.

Gibson, M.1998. Dialect Contact in Tunisian Arabic: sociolinguistic and structural aspects. Ph.D. Thesis. Reading: University of Reading.

Górska, K.; Jurek, M. 1979. Emprunt lexicat esquise de l'état de recherche. Studia Romanica Poznaniensja 5, 109-120.

Jabeur, M. 1987. A Sociolinguistic Study in Rades: Tunisia. Ph.D. thesis. Reading: University of Reading.

Łacina, J. 1989. Współczesna specjalistyczna terminologia arabska i procesy słowotwórcze na przykładzie słownictwa z dziedziny chemii, fizyki i technik. Poznań: Uniwersytet im. Adama Mickiewicza.

Talmoudi, F. 1981.Texts in the Arabic Dialect of Sûsa (Tunisia). Göteborg: Acta Universitatis Gothoburgensis.

Waszakowa, K. 2001. O rozumieniu najnowszych zapożyczeń. W: Michalewski, K (red.). 2001. Współczesna leksyka. Cz. II. Łódź: Uniwersytet Łódzki, 156-167.

Zaborski, A. 1982. Dialekt egipski języka arabskiego. Kraków: Uniwersytet Jagielloński.

Zabrocki, L. 1956. Związki językowe niemiecko-pomorskie. (Dotychczasowe badania). W: Konferencja Pomorska (1954). Prace Językoznawcze. Warszawa: Państwowe Wydawnictwo Naukowe, 149-174.

Zabrocki, L. 1963. Wspólnoty komunikatywne w genezie i rozwoju języka niemieckiego, t, I. Prehistoria języka niemieckiego. Wrocław: Ossolineum.

Zavadovskij, Ju. 1962. Arabskie Dialekty Magriba. Moskva. 